\title{
Statistical Pitfalls: Problems with the Statistical Representation of Fieldwork Data from Social Research
}

\author{
Okeke, ClO \\ Faculty of Education, University of Fort Hare \\ cokeke@ufh.ac.za \\ Adu, EO \\ Faculty of Education, University of Fort Hare \\ eadu@ufh.ac.za
}

\section{Doi:10.5901/mjss.2014.v5n20p1448}

\begin{abstract}
Students, as well as professional research proposals have been rejected by the proposal committee and some grants awarding bodies for lack of statistical representation. Statistics is the science that is dealing with the collection and organisation, analysis and interpretation of numerical data from which conclusions about the variables under study, are made. This contribution to the pathway to ensuring students' success argues that it would be misleading and inappropriate to suggest that only studies, which are backed-up with statistical tools, are rigorous and meaningful. Previous research has argued that statistical techniques play crucial role for uncovering hidden knowledge. However, in the present paper, the researchers argue that to assign such potency to statistical tools appear misleading especially to students and newer researchers. The paper notes that of about twenty-three statistical tools available for use by researchers, none possesses any investigative quality. What statistics possesses is an analytic strength, whereby numerical and calculative meanings are assigned to assembled data that cannot uncover beyond the strength of the data-collecting instrument. In this paper, the researchers examine the meaning of statistics, the use of language as a tool of statistics, statistical data and its types; scale of measurement and appropriate statistics, and some of the pitfalls in the use of statistical tools in analysing data from social and behavioural studies. The implication of this for students' research and success are equally highlighted.
\end{abstract}

Keywords: fieldwork data, statistical analysis, social research, scale of measurement, statistical pitfalls

\section{Introduction}

The lethal predisposition of mankind to leave-off thinking about a thing when it is no longer doubtful is the source of half their errors. According to Hammersley (1989, p. 23), "human phenomena are unique...they do not fit neatly into abstract categories. Attempts to reduce them to such categories involve loss of their most distinctive features". Abstract categories involve the "...conceptualization of human behavioural characteristics in terms of variables, which attempt to draw inferences from sample to population that are then represented in the form of mathematical and statistical inferences using figures" (Okeke, 2010c, p. 43). The most commonly used tools in this exercise are the descriptive and inferential statistics. It would appear that such attempts to abstract human constructions, squeezes out the meanings that are immanent in these behavioural characteristics. This paper derives from a review of extensive literature on the use of statistical tools in the analyses of data resulting from social and behavioural studies within the Faculties of Education of some selected universities in Nigeria.

\section{Epistemology of Data Generation}

The debates on research methodology have a very long history dating back to the $18^{\text {th }}$ and $19^{\text {th }}$ centuries' philosophy of science (Hammersley, 1989; Wagner \& Okeke, 2009). These debates centre on the source and nature of scientific knowledge. Notable philosophical currents of the period in question include: Positivism; Historicism; Neo-Kantianism; and Pragmatism. It is noteworthy that from these worldviews important ideas leading to the development of major theoretical paradigms including Functionalism; Marxist-conflict; and Symbolic Interactionism emerged (Shepard, 1990). However, for many theorists the developments represent a case between two competing paradigms (Wainwright, 1997; Volscho, 2001; 
Sandelowski \& Barroso, 2002). Others simply view such development as a matter of differential research methods with varying degrees of benefits as well as pitfalls suited for conducting particular kinds of social research (Star, 1998; Stewart \& O'Neill, 1999; Ward, 1999).

Today, it is possible to reduce the epistemological variance into which research dichotomy has degenerated to "two polar extremes each reposing upon different fundamental philosophical assumption about the way we acquire knowledge about our environment" (Worsley, 1985, p. 74). That is why contemporary research speaks in terms of positivism versus humanism; determinism versus interpretivism; hypothetico-deductivist versus inductivist; and of course, quantitative versus qualitative. For sure, these philosophical developments of the $18^{\text {th }}$ and $19^{\text {th }}$ centuries laid very important foundation for the polarisation of research understanding and enterprise of the later centuries. For instance, positivists retained from the said centuries' philosophy of science, the idea of the natural law with its conception that the central aim for the study of society or phenomenon is to discover universal laws. Positivists also retained from this philosophical tradition, the idea that science is the only true source of knowledge (Hammersley, 1989). This conception of knowledge led the positivist researchers to the idea of the application of methods similar to those used in the natural sciences. It is equally from this tradition that the idea of quantitative and statistical representations of the empirical social world began (Wagner \& Okeke, 2009; Okeke, 2010c).

Thus, to get on with research, it would appear all the researcher needs "is knowledge of previous research and of statistics" (Mennell, 1974, p. 1); this tradition operates from within the hypothetico-deductive framework, and this was very influential in the conduct of educational research well into the 1950s and 1960s. Within the frame of natural sciences research, it is important to note that generated data are classified as inanimate. The focus of the natural sciences research centre on non-living systems as in physics, astronomy, geology, and chemistry; this is distinct from social sciences, which focus on human beings. The field for the natural sciences research is usually and necessarily the laboratory and the most obvious language in use is usually that of atoms and molecules. Data, which emerge from such process, are inanimate (denoting non-living things) and usually quantitative because the researcher simply applies various scales of measurement and attaches numerical significance to various observed occurrences.

Taken together, all positivists share certain principles in relation to scientific knowledge and belief that, research enterprise must be accompanied with some elements of controlled experimentation; should show a clear demonstration of researcher objectivity and a total detachment from the subjective; replicable evidence of the predictability and generalization of research findings; and finally, that all scientific research enterprise must be value free (Obikeze, 1990). It must be noted that social sciences researchers adopted the above mode of conception of knowledge from the natural sciences (Wagner \& Okeke, 2009). Researchers within such philosophical orientation rely on controlled and systematic observation of its subject matter as well as on systematic collection and analysis of data (Okolocha, Nwanunobi \& Igbo, 1999). It is this type of orientation that guides the positivists' conduct of research and during this process, persons or events are broken down into discrete parts for study; these discrete parts are directly observable units with behaviour that is separate from and unaffected by the observer (Brink, 1991).

However, anti-positivist researchers, influenced by historicist, neo-Kantian and pragmatist philosophies, dismiss the positivists' assumptions as speculative and reductionistic (Wagner \& Okeke, 2009). Taken jointly, the anti-positivists believe that human life is so diversified and, as such the positivists' physical expressions of it, is highly inappropriate for the understanding of these diversified forms of life. They therefore place emphasis on a deeper investigation of underlying meanings in order to uncover the distinctive cultural dynamics from which such forms of life had evolved. Antipositivists are interested in analysing the conditions under which knowledge is produced while recognising that observers within the social and physical world can do so only through paying attention to the distinctive character of humans.

It must then be noted that the central theme in the humanists' epistemology is the understanding of the distinctive nature of human social interactions. It is important to note also that such epistemology was very influential in the development of what is today regarded within research parlance as the qualitative approach. The word qualitative implies recognition of the processes and meanings that are not easily susceptible to measurement in terms of quantity, amount, intensity or frequency (Carney et al., 1997). Its emphasis is on capturing or obtaining in-depth understanding of the participants' actions in a particular study. Qualitative approach represents all forms of research that are linked with the humanistic or interpretive approaches including phenomenology, ethnography, ethno-methodology, heuristics and hermeneutics (Glesne \& Peshkin, 1992). According to Brink (1991, p. 14), in qualitative research "there is attention to the social context in which events occur and have meaning, and there is emphasis on understanding the social world from the point of view of the participants in it". Data, which emerge from such process, are usually and necessarily animate data - denoting living things because such data often result from research processes involving human beings. Such data are what Hammersley (1989) earlier noted, do not fit neatly into abstract categories because such data are not easily readily susceptible to quantification and measurement; doing so would certainly squeeze off their meanings. Employing or 
asking statistical tools to do any form of analyses of such data therefore would most likely produce findings that are deceptive.

While the above epistemologies continue to inform the way research data are generated, the question, which resonates from discussions in this subsection borders on whether research professionals and academics, and researchstudents are familiar with such $18^{\text {th }}$ and $19^{\text {th }}$ centuries historical and philosophical assumptions underpinning data generation. As we shall discover in the subsection dealing with implications for students' success, the adoption and usability of a particular research approach, theory or concept could be fundamentally distorted, and sometimes completely ridden by wrong assumptions when one is not properly grounded in the history of such approach. Obviously, this proposition may offer a useful research agenda especially considering the fact that the survey, which has influenced this paper, suggests that research-students (and their lecturers) may not be aware of those historical antecedents of the $18^{\text {th }}$ and $19^{\text {th }}$ centuries' philosophy of science. The implication is that methods are simply in use without their users knowing anything about the origin of such methods.

\section{What Statistics Means}

By definition, statistics is "the science dealing with the collection, organization, analysis and interpretation of numerical data, and drawing conclusion about a phenomenon under study" (Olaitan \& Ndomi, 2000, p. 1). It is the study of data. It includes descriptive statistics (the study of methods and tools for collecting data, and mathematical models to describe and interpret data) and inferential statistics (the systems and techniques for making probability-based decisions and relatively accurate predictions. Statistics has its roots in the idea of the state of things' or etymology. The word itself comes from the ancient Latin term statisticum collegium, meaning 'a lecture on the state of affairs'. Eventually, this evolved into the Italian word statista, meaning 'statesman', and the German word Statistik, meaning 'collection of data involving the State'. Gradually, the term came to be used to describe the collection of any sort of data (Croanian \& Liywelyn, 2013. p.4). As one would expect, statistics is largely grounded in mathematics, and the study of statistics has offered itself to many major concepts in mathematics including probability, distributions, samples and populations, the bell curve, estimation, and data analysis.

According to Adu and Ogunleye (2006), there are four purposes of statistics. These are to:

- reduce large quantities of data to manageable and understandable form;

- aid in the study of population and samples;

- aid in making reliable inference from observation data, and

- $\quad$ aid in decision making.

Whatever is the source of data, whether from routine collection, planned surveys or planned experiments, it is raw and meaningless until it is treated statistically. An important purpose of gathering data is to provide information, and based on the data accumulated and information provided, a lot of far-reaching decisions can be taken. To do all these, there is need for the use appropriate statistical tools. Over the years the emphasis and manner with which statistics has been applied in the analysis of obtained information has left much to be desired. It is hoped that this paper would add to the debates around the use of statistical tools when analysing fieldwork data from human studies.

There are in all about twenty three (23) statistical tools available for use to the quantitative researcher. These are percentages; t-test; ANOVA (1-way); Chi-square; Pearson correlation; multiple regression analysis; ANOVA (2-way); Zscore; test of proportions; ANCOVA; factor analysis; man Whitney u-test; Weighted average; Durbin-Watson; KruskalWalis; Sign rank test; Pareto; Co-efficient of variation; Canonical correlation; Cochran test; and, MANOVA (Onugha, Betiku, Salau \& Chukwu, 1995, p. 9). However, recent survey by these researchers has revealed that most of the abovementioned statistical tools are rarely used by researchers. The most commonly used being the percentages, ANOVA, ANCOVA, chi-square, t-test and the Pearson correlation. The above finding appears to be in line with an earlier finding by Onugha et al. (1995), which also note that of the twenty-three (23) statistical tools already mentioned, the ANOVA, t-test and the percentages are popular amongst research-students and professionals.

Perhaps more striking about Onugha et al. (1995) study, is their revelation concerning the roles of statistical tools to research, as well as that of their argument on the fallibility of human judgment concerning same. The study, which is also known as the NERDC Study was captioned 'A critique of statistical tools used in selected Journal Articles in research in education' was conducted by staff of the Nigerian Educational Research Development Council (NERDC) to ascertain the nature and manner with which statistical tools were used in terms of frequency of use, relevance and adequacy (Onugha et al., 1995). It made use of four research questions, and the questionnaire instrument was designed by the academic staff of the Statistics Department in the NERDC office to obtain information regarding certain journal articles 
published in Nigeria. In all 300 articles published between 1980 and 1993 were reviewed by the members of the project team. It is not known from the article for how long the study lasted other than the fact that it was completed in November 1994 and published in 1995. But the data obtained by Onugha et al. (1995) during their fieldwork were analyzed using the frequency counts and percentages. At the end, certain important issues were raised by Onugha et al. (1995).

First, was the issue of the role of statistical tools to research? The NERDC study suggests, "Statistical techniques play crucial role...for uncovering through the vehicle of research, hidden knowledge" (Onugha et al., 1995, p. 4). But we argue that statistics does not possess an investigative quality, what it possesses is an analytical strength whereby numerical and calculative meanings are given to already assembled data resulting from an already concluded fieldwork. It therefore does not uncover beyond that which the data-collecting instrument has offered at the end of a fieldwork. Like the sorting and coding processes of the qualitative research, statistical tools ensure that order is brought into an otherwise voluminous set of data. But unlike the qualitative research where narrative description, sequential analysis, analytic induction, may be used to interpret sorted and coded data, statistical tools are used to assign meanings to the quantitative data. This process does not uncover beyond the strength of the data-collecting instrument (Okeke, 2003; 2010c).

A second issue raised by the NERDC study, was that bordering on human judgment. According to Onugha et al. (1995, p. 4), "when human judgment is used as a measuring instrument, it becomes expedient to ask questions bearing on the validity and/or appropriateness of the statistical tools employed for particular situations". Equally, we argue in line with Okeke (2010c) that nothing exists in knowledge that is not a product of human judgment, theoretically and practically. But this has remained contentious in the qualitative and quantitative debate amongst researchers. The argument being that quantitative research processes rely on well established schemata (which of course are products of human judgment) while qualitative research processes rely on the interpretive strength of the individual researcher. Notwithstanding, we also argue that the process through which validity as research principle is reached is usually and necessarily based on human judgment. It is this sort of understanding, which appears to portray contemporary research endeavour as unnecessarily and overly statistical, irrespective of the knowledge and understanding the user has on the tools.

Thus, having narrowly defined research enterprise as one activity that must be statistically oriented, a kind of conscious war of legitimation is created within most research traditions the world over. Resulting from this culture of legitimation is the indiscriminate use of statistical tools - a finding also noted by the NERDC study when it found that the "wrong use of the F-ratio and Chi-square statistics was common and these two statistics were interchangeably used thereby suggesting the investigator's lack of understanding of the basic assumptions underlying their correct usage" (Onugha et al., 1995, p. 3). In the survey of selected theses completed in some universities in Nigeria (Okeke, 2002; 2009b), it was also discovered that in an attempt to become 'legitimate researcher', students embarking on research simply adopt statistical tools irrespective of the nature of the phenomenon under investigation as well as their competence in the use of such tools. This problem was clearly visible in all the twenty (20) theses reviewed during the said survey; one then wonders whether research is conducted because the researcher wants to show his/her statistical prowess or because the researcher identifies problems within the social system, and then attempts an intellectual understanding of such problems in order for him/her to provide some solutions that may have important policy implications within that social system. In line with the foregoing analyses, we learn four major reasons why statistical tools are not capable of representing data from the empirical social world without very serious and fundamental errors. But before then let us look at the use of language as a tool of statistics.

\subsection{Use of Language as a tool of Statistics}

There is need for accurate data (statistics) to produce accurate research reports, evaluate it and communicate it to others. Also required is the right information at the right time to be able to achieve desired results. All research to be generally useful, must ultimately be issued as a written document. To be able to produce such a document, the researcher must possess the ability to produce such document; the researcher must possess the ability to use language to communicate with a degree of skill, competence and accuracy that will clearly delineate all aspects of the research process. The basic requirement for writing such a report is the ability to use the official language communication effectively, to write clear, correct exposition so that the document will leave no doubt in the reader's mind precisely on what the research problem is and what steps and considerations resulted in its solution.

In the research report, the discussions and findings must be presented with such clarity that it will be impossible not to understand precisely the results of the investigation. This is possible in the face of vocabularies that are adequate for the common exigencies of exposition. No one speaks or writes clearly who does not think clearly. Clear thinking is 
based on the ability to think logically, sequentially and correctly. We write the way we do because we think the way we do. Good writing is merely precise, sensitive thinking mirrored in carefully chosen, logically presented words. The beauty of research could be destroyed if the analyses and findings are not correctly presented. Such presentation is the end result which can make or mar the total research report. Language command and language use are essential tools of research and statistical reporting (Akinwumiju \& Osiki, 2006)

\subsection{Statistical Data and its types}

\subsubsection{Qualitative data}

Qualitative data in statistics is often used interchangeably with categorical data. It is a definite measurement expressed not in terms of numbers, but rather by means of a natural language description.

For example: Favorite color = "brown"

Height = "short"

Although we may have categories, the categories may have a structure to them. When there is not a natural ordering of the categories, we call these nominal categories. Examples might be gender, race, religion, or sport. When the categories may be ordered, these are called ordinal variables. Categorical variables that judge size (small, medium, large, etc.) are ordinal variables. Attitudes (strongly disagree, disagree, neutral, agree, strongly agree) are also ordinal variables; however we may not know which value is the best or worst of these issues. Note that the distance between these categories is not something we can measure.

\subsubsection{Quantitative data}

Quantitative data is a numerical measurement expressed not by means of a natural language description, but rather in terms of numbers. However, not all numbers are continuous and measurable. For example, the social security number is a number, but not something that one can add or subtract. Let us look at the same example as above but in qualitative term. For example: Favorite color = "380 nm"; Height = "1.6 m".

\subsubsection{Quantitative data always are associated with a scale measure}

Probably the most common scale type is the ratio-scale. Observations of this type are on a scale that has a meaningful zero value but also have an equidistant measure (i.e., the difference between 10 and 20 is the same as the difference between 100 and 110). For example, a 10 year-old girl is twice as old as a 5 year-old girl. Since you can measure zero years, time is a ratio-scale variable. Money is another common ratio-scale quantitative measure. Observations that you count are usually ratio-scale (e.g., number of widgets). A more general quantitative measure is the interval scale. Interval scales also have an equidistant measure. However, the doubling principle breaks down in this scale (Croanian and Liywelyn, 2013, p.13).

\subsubsection{Statistical data can also be classified as either primary or secondary}

Primary data means original data that has been collected specially for the purpose in mind. It means someone collected the data from the original source first hand. Data collected this way is called primary data. The people who gather primary data may be an authorized organization, investigator, enumerator or they may be just someone with a clipboard. These people are acting as a witness so primary data is only considered as reliable as the people who gathered it. Research where one gathers this kind of data is referred to as field research as is the case with the questionnaire instrument. The other type is the secondary data. A data that has been collected for another purpose is called secondary data. When we use statistical method with primary data from another purpose for our purpose we refer to it as secondary data. It means that one purpose's primary data is another purpose's secondary data. Secondary data is data that is being reused in a different context. Research where one gathers this kind of data is referred to as desk research as with reading for the purpose of collecting data from a book.

\section{Scale of Measurement}

The four general types of scales of measurement are nominal, ordinal, interval, and ratio. 
(i) Nominal: this scale gives categorization without order, whatever is being measured is categorized into two or more classifications that indicate only differences with respect to one or more characteristics. An example is the sex of an individual, which can be either male or female

(ii) Ordinal: in addition to indicating difference, this scale also orders the scores on some basis, such as low to high or least to most. Although the scores are ordered, equal intervals between scores are not established. An example is attitude towards school.

(iii) Interval: in addition to order, equal units or intervals are established in this scale, such that a difference of a point in one part of the scale is equivalent to a difference of one point in any other part of the scale. An example is the thermometric measurement, that is, thermometer for reading temperature.

(iv) Ration: in addition to an equal unit, this scale contains a true zero point that indicates a total absence of whatever is being measured. Examples include a tape rule, ruler and monetary expenditures for various school functions etc

This scale according to Alegbeleye and Fabunmi (2006) comprise a hierarchy of measurement levels, which are based on the amount of information contained in the score or the measure generated by the scales. The scale of measurement adopted for a research determines the statistical design to be used. The table below contains appropriate statistics for each scale

Appropriate statistics for each scale of measurement

\begin{tabular}{|l|l|}
\hline Scale & Appropriate Statistics \\
\hline Nominal & Mode, Percentage, Chi-square \\
\hline Ordinal & Mode, Median, Percentile, Percentage, Chi-square, Rank correlation \\
\hline Interval & Mode, Mean, Standard Deviation, t-test, f-test, and Product Moment Correlation \\
\hline Ratio & $\begin{array}{l}\text { Geometric mean, Percent variation, Linear Regression, Multiple Regression, Analysis of Variance, } \\
\text { Analysis of Co-variance, and all other statistics }\end{array}$ \\
\hline
\end{tabular}

Source: Alegbeleye and Fabunmi (2006)

Several educational variables cannot be categorized into the hierarchy of scales especially into ordinal and interval scales. At times it is difficult to define the equal unit or interval absolutely. The intervals may be established on the basis of convention and usefulness. A basic concern is whether the level of measurement is meaningful and that the implied information is quantified. For example, if twenty items reflect a student's attitude toward school, each item scored 1 to 5 on a scale from "strongly disagree" to "strongly agree". The items are in the same direction in a manner that a high score indicates the more positive attitude. If the item scores (numerals assigned to the responses) are summed, will this sum represent the interval scale measurement? Some scholars would agree that it does, and it does if appropriate meaning can be assigned to the sum. The meaning depends on both the conditions and variable of the specific study.

\section{Statistical Pitfalls}

First, statistical tools and methods of analyses, insofar as they deal with numbers that are sometimes represented in abstract terms, are not capable of dealing with those aspects of human conduct, which call for creativity and innovation. This statistical inadequacy was most noticeable in the study of 'young children's understanding of the concept of time' by Odogwu (1993). This is one of the completed theses reviewed during the survey that has influenced this paper. Odogwu's (1993) study was intended to cover all primary five and six pupils in Lagos metropolis of Nigeria. A total of 206 pupils were sampled for the study. Odogwu (1993) developed the Integral Time Concept Test; Mathematical Time Concept Test, Socio-economic Background Questionnaire; and Questionnaire on Teachers' Method of Teaching Time, for the purpose of data collection. The descriptive and inferential statistics were used to analyse collected data. In all, a total of sixty-four (64) statistical tables were constructed.

Although this article is not designed to discredit any particular approach to investigating the empirical social world, however, it would appear conventional wisdom holds that the investigation of certain social phenomenon demands a particular kind of fitting approach. Following this, a study which was informed by the desire to learn the young children's understanding of time, should have sought for an approach that would enable such researcher to ascertain the deeper meanings and explanations of the concept of time amongst those children who took part in the study. It is my argument that the unstructured in-depth interviewing used effectively would have enabled Odogwu's work to achieve this task. Equally, the observational technique may have offered a more useful clue toward the understanding of the young 
children's practice and management of time because every activity within a school setting appears to be time-guarded.

It is therefore the argument of this article that the weaknesses of the various questionnaires developed by Odogwu (1993) lie mainly in their failure to "ascertain the deeper underlying meanings and explanations of the concept of time and the various factors related to its development" (Okeke, 2010c, p. 29). In addition to the above, it is important to add following Collins (1998) that life does not consist of data, it consists of stories and these stories are negotiated during social interaction involving another life or lives. Consequently, to approach the study of the 'young children's understanding of time' through pre-constructed structured questionnaires not only denied life that unique quality but also it would have concealed more than it intended to reveal. Furthermore, Odogwu's use of sixty-four (64) statistical tables to represent the test scores, gives one the impression that in spite of the constructed character of those instruments, and the potential errors that might have been built into them, there is a sense in which these statistical techniques are used as if they constitute a machine for transforming information from data into valid conclusions (Hammersley \& Gomm, 1997). What is more, the argument here appears to offer a very fertile ground for research on the vulnerability of the quantitative claims to validity and reliability of its findings. As a result of the above neglect, statistical analysis is found wanting in those areas which call for an understanding and production of generic principles, which inform the individuals' dynamic and differential natural propensities.

Second, because emphasis is on numeracy, statistical inferences fail in capturing the complex but informing nature of the subjective side of human actions, which is essential for the understanding of human behavioural characteristics. Statistical inferences are drawn from mostly data from snapshot processes like that coming from the questionnaires. It does not require data from methods that have sought an understanding of the emic aspects of the individuals' behavioural characteristics. As a result of this seemingly superficial modes of analyses, statistical tools do not recognize or rather demonstrate that the researcher has been genuinely involved in any form of longitudinal and in-depth search. Moreover, the statistical computation, which usually follows such data collection, may not be immune to the manipulative skills of an unscrupulous quantitative researcher.

Third, most, if not all statistical analyses are based on questionnaire-dominated fieldworks, which are often an onthe-spot one way kind of administration of such questionnaires, often lasting for just one day and even few hours. Such processes are usually static situations, and not processes developing over time. However, unlike in the fieldwork that is qualitatively oriented, where the researcher is involved in a continuous sense-making, and field-making analytical processes with an interplay between the objective and the subjective, statistical representation of data is based on the outcome of often extremely controlled experimental or quasi-experimental processes. To this end, Hammersley (1989) suggests that the dynamic and fluid nature of the human behavioural characteristics do not permit any meaningful statistical representation of such phenomenon because statistical tools can only give correlational but not causal explanations regarding the actual situation under investigation.

Fourth, and finally, statistical languages are exclusive preserve for those who have been privileged to receive training regarding the interpretation of it. This is in line with the findings of Onugha et al. (1995), which note that the highly specialized language and discipline required in statistics, makes it imperative that only those initiated into it can interpret it effectively. If this is true and if it is equally true that research enterprise within Nigeria educational institutions, and else where, is overly statistical, how then one may ask, could findings, which are meant for those who are statistically illiterate, be interpreted? Where such findings are meant to serve some kind of emancipatory roles as in feminist studies and mass literacy programmes, statistical representation of such findings might make the entire research process to appear meaningless to such class of end-users who have not received any form of training in statistics. How then can we take care of these groups of people within a research tradition that is engulfed in a culture of statistical legitimation?

\section{Implications for Students' Success in Research Practice}

In a recent study, Wagner \& Okeke (2009, p. 61) note that when doing research,

Choosing between methodologies (or even combining methodologies) does not necessarily imply an attendant philosophical framework and argue that constructors and/or teachers of research courses need to be more aware of unexamined ontological and epistemological assumptions and about what we subsequently teach students.

So far in this paper, the underlying epistemological antecedents leading to the conception of research in terms of quantitative or qualitative among other issues have been discussed. However, although some writers suggest that there is no longer any justification for a dichotomy between both research approaches (see Patton, 1996; Wagner \& Okeke, 2009); in the current paper, recognition is offered to this paradigmatic duality as a necessity for the third wave expressed 
by proponents of triangulation. The reason is that such dichotomy offers room for continuous divergence of opinions on the ways researchers perceive the empirical social world. But it is equally noted that the epistemological relationship between both research approaches appears to be that of one serving as handmaid to the other. The "qualitative methodologies' non-susceptibility to statistical quantification and manipulation...account for the reason why this research paradigm is still being treated as second-rate" (Okeke, 2009a, p. 5), and this relationship between both research paradigms, appears to resonate our pedagogical and supervisory relationships with our students when we teach and practice research. The question, which remains to be asked, is whether a university can afford to graduate students who are prepared to do research through one single research approach. More so, what ethical issues are there for academics that impose their own preferred research method upon their students?

One major aim of the research method course is to produce students who are not only knowledgeable in the processes of research practice but to apply same in carrying out their own research activities. Such programme must aim at equipping students who on graduation would serve as professional researchers within their areas of specialization; those professionals who would learn to use the skills they have learnt from school to conduct research works either as independent researchers or as employed research fellows within existing academic or research institutes. Researchers and research teachers who impose a particular approach to research upon their students appear to narrow the intellectual horizon of such students on graduation. Thus, rather than being skilled and thoughtful researchers, knowledge of one single research paradigm be it quantitative or qualitative would prepare deskilled researchers.

\section{Conclusion}

Evidence (Okeke, 2002) has shown that over representation of works in statistical terms and over reliance on statistics, appears to cause many researchers to lack the ability and descriptive power to adequately explain the contributions of the variables (say to particular educational problem), which their studies originally have set out to explicate. This then gives the impression that such researchers simply embark on research in order for them to show their statistical prowess and then earn academic recognition in the form of degrees for doing so. However, there are ontological and epistemological choices to be made by both the research academics and their students when teaching and practicing research. On the part of the students, we argue that students and other developing researchers should be equipped and encouraged to make their own decisions and choices, not just methodologically but also epistemologically and pragmatically.

When studies are aimed to raise the awareness or consciousness of the participating individuals, and the public (as is usually the case with empowering and emancipatory research), it is imperative that the emerging findings and reports should be written in the language that is common to all. It would seem this is the only way proper meaning and understanding is brought into such a research endeavour while ensuring that the rationale for such a project is achieved. These authors therefore would like to prompt reflection among research methods teachers in our universities about what informs the decisions they make regarding the way they construct their research method courses, and on the way they go about teaching and supervising their students.

\section{References}

Adu, E.O. \& Ogunleye, B.O. (2006). Analysis of covariance. In G. O. Alegbeleye, I. Mabawonku \& M. Fabunmi (Eds) Research methods in education. Ibadan: University Printers. Pp. 382-397

Akinwumiju, J. A. \& Osiki, J.O. (2006). Statistical tool for analysis and interpretation. In G. O. Alegbeleye, I. Mabawonku \& M. Fabunmi (Eds) Research methods in education. Ibadan: University Printers. Pp. 211-247

Alegbeleye, G.O. \& Fabunmi, M. (2006). Instrumentation and data collection. In G. O. Alegbeleye, I. Mabawonku \& M. Fabunmi (Eds) Research methods in education. Ibadan: University Printers. Pp. 211-247

Carney, J. H., Joiner, J. F., \& Tragou, H. (1997). Categorizing, coding and manipulating qualitative data using the Word Perfect Word Processor. The Qualitative Report, 3(3). Retrieved from: http://www.nova.edu/ssss/QR/QR3-3/carney.html

Collins, P. (1998). Negotiating Selves: Reflections on Unstructured Interviewing. Sociological Research Online, 3(3). Retrieved from: http://www.socresonline.org.uk/socresonline/3/3/2.html

Croanian C., \& Liywelyn, H. (2013). An introduction to statistics. Wiki books. Open books for an open world. Retrieved from http://en.wikibooks.org/wiki/Statistics/Introduction/What_is_Statistics

Hammersley, M. (1989). The dilemma of qualitative method: Herbert Blumer and the Chicago tradition. London: Routledge.

Hammersley, M., \& Gomm, R. (1997). Bias in social research. Sociological Research Online, 2(1). Retrieved from: http://www.socresonline.org.uk/socresonline/2/1/2.html

Odogwu, H. N. (1993). The Concept of Time Among Primary School Pupils and Factors Related to its Development. Unpublished doctoral thesis. Lagos: University of Lagos, Nigeria.

Okeke C. I. O. (2002). A Survey of Research Traditions in the Faculty of Education of Selected Nigerian Universities. Unpublished paper, 
Department of Educational Foundations. Nsukka: University of Nigeria.

Okeke, C. I. O \& Ume, T.A (2004b). Some epistemological issues in the conduct of social and behavioural studies in the Faculty of Education of Nigerian Universities. The Qualitative Report, 9 (2) 320-334. http://www.nova.edu/ssss/QR/QR9-2/okeke.pdf

Okeke, C. I. O. (2003). The Gendered perception of schooling amongst sec. school students: A qualitative approach. Unpublished doctoral thesis. Nsukka: University of Nigeria.

Okeke, C. I. O. (2009a). The experiences with qualitative validity in a classroom research: Issues Pertaining to value claims. EDUCARE: International Journal for Educational Studies, 2(1): 1 - 16.

Okeke, C. I. O. (2009b). Issues pertaining to the theoretical framework of a study: Reflections from some universities in three African countries. The Nigerian Journal of Guidance \& Counseling, 14(1): 58 - 70.

Okeke, C. I. O. (2010b). Guilty or Not Guilty? How Nigerian homes impede the aspirations of Nigerian girls for higher education. USChina Education Review, 7(6), 16 - 30.

Okeke, C. I. O. (2010c). Gender and schooling: A qualitative study of teens' perception of schooling in a Nigerian suburb. Germany: VDM Publishing House.

Okeke, C. I. O. (2010e). An encounter with the supervisor's and institutional discourses: A personal reflective account. Southern African Review of Education, 16(1), $114-130$.

Olaitan, S. O., \& Ndomi, B. M. (2000). Vocametrics: A High-Tech Text with Computer Skills. Onitsha: Cape Publishers.

Onugha, D.C., Betiku O.F., Salau, M.O., \& Chukwu, G.N. (1995). A critique of statistical tools used in selected journal articles in research in education, Journal of the Nigerian Educational Research and Development Council, No. 4.

Sandelowski, M., \& Barroso, J. (2002). Reading qualitative studies. International Journal of Qualitative Methods, 1(1). Retrieved from http://www.ualberta.ca/-ijqm

Star, S.L. (1998). Grounded classification grounded theory and faceted classification. Library Trends, 47(2), $218-231$.

Stewart, P., \& O'Neill, M. (1999). Critical literacy: A qualitative investigations of some conceptualization, practices and implications for English teaching. Education Research and Perspective, 26(2), 127-147.

Volscho, W.T. (2001). Marxist concepts of exploitation and inequality. Radical Pedagogy. Retrieved from http://www.sspp.net/

Wagner, C. \& Okeke, C. I. O. (2009). Quantitative or qualitative: Epistemological choices in research methodology curricula. In M. Garner, C. Wagner and B. B. Kawulich (Eds.) Teaching research methods in the Humanities and the Social Sciences. London: Ashgate.

Wainwright, D. (1997). Can sociological research be qualitative, critical and valid? The Qualitative Report, 3(2). Retrieved from http://www.nova.edu/ssss/QR/QR3-2/wain.html

Ward, B. (1999). The edited topical life history: Its value and uses as a research tool. Education Research and Perspectives, 2(2), 45-60. 